As a matter of fact, it would not be difficult to find scores of just such mixed professorships and instructorships in colleges all over this country. I think it would be safe to assert that it is only in the larger universities, relatively few in number, that specialization has been carried to anything like the degree suggested.

The cases of the colleges in this state may be cited as examples. In one, geology is taught by a professor of astronomy, in another by a professor of agricultural chemistry; in a third a professor of chemistry teaches mineralogy. And it is only fair to these several professors to say that in each case the instruction given is excellent.

That Maine is not unique in this respect is indicated by notices of vacancies in college faculties that have come to my attention during the past two years. In one case an instructor was needed in chemistry and geology, in another an associate professor in zoology and geology, in colleges one of which was near the Atlantic coast (not in Maine), and the other not far from the Pacific.

In my own teaching experience I held for a number of years a position in which I was expected, and did make a brave attempt, to teach chemistry, geology, botany and zoology, with a little physics thrown in for good measure; this in an institution which would be called a college almost anywhere outside of New England.

There are potent reasons why this condition of affairs exists still, and must go on existing for some time to come, whatever may be said as to its desirability; the most obvious being the limitations placed upon our colleges by lack of money. However, I am not altogether certain that the condition is undesirable.

I realize, of course, that Professor Gortner and $I$ are not thinking of exactly the same thing. His attention is, naturally, on the more advanced courses, in which students are, and should be, in charge of more or less narrow (I use the word in no derogatory sense) specialists; mine is on the more general courses, in the conduct of which teaching ability and personality are at least as important as erudition. There is still a large and important field for the old natural-history type of instructor, and
I for one sincerely hope that his species will not soon become extinct.

Central Maine Power Company,

Freeman F. Burr Augusta

\section{SHARK AND REMORA}

To the Editor of ScIEnce: The account by Dr. Spaeth in Scifince of October 21 of symbiotic relations between a shark and a remora recalls some observations made by the writer in San Diego, Cal., in November, 1920. The head of a Tuna Shark, Isuropsis glauca, had been cut off by the writer and carried to the laboratory of the Scripps Institution, at $\mathrm{La}$ Jolla. After some dissections had been made there was found on the table a small remora, three inches long, that had evidently taken refuge in the mouth or gill-chamber of the shark.

Grinneli Coliege

H. W. NORRIS

\section{SCIENTIFIC BOOKS}

Life of Alfred Newton, Professor of Comparative Anatomy, Cambridge University, 1886190\%. By A. F. R. Wollaston. With a preface by SIR ARohibald GeIrIe. New York: E. P. Dutton \& Co., 1921. 332 pp.

The loose organization of English University affairs, the lack of coherence in the scheme of the institutions, have had their advantages and disadvantages. When in Cambridge a number of years ago, I met an eminent writer whose original and heterodox ideas about religion had lately been published in a book. "What do the orthodox divines of the University think of him?" I asked a resident. "They do not even know that he exists!" Perhaps that was a slight exaggeration, but the independence of the teachers is such that they do very nearly as they please, and wax or wane in reputation and even income according to their ability to command attention or win support. The centrifugal tendency has dominated the intellectual life of the place, increasing with the inevitable specialization of modern times. Each department is, as it were, at the end of a long lane, which no one 